\title{
A MULHER E A CRÍTICA: ASPECTOS E QUESTÕES NA FORTUNA CRÍTICA DA MARQUESA DE ALORNA
}

\author{
Joana Junqueira Borges ${ }^{1}$
}

Resumo: D. Leonor de Almeida Portugal Lorena e Lencastre (1750-1839), a Marquesa de Alorna, foi uma poeta, tradutora e ensaísta portuguesa e muito embora seja facilmente observável como a presença feminina foi deixada de lado na história da literatura portuguesa, essa mulher se fez presente em diversos manuais literários. A partir do estudo que vem sendo desenvolvido sobre sua atividade tradutória, o presente artigo pretende voltar ao passado em busca de vestígios de sua presença como autora na crítica histórico-literária para, então, analisar em que medida os registros de sua produção colaboram para uma compreensão de sua obra, ou se a crítica literária apenas corroborou o papel secundário que a história, seja ela da literatura ou universal, deu à mulher.

Palavras-chave: Marquesa de Alorna, crítica literária feminina, história literária feminina

\section{WOMEN AND CRITICISM: ASPECTS AND ISSUES ON MARQUISE OF ALORNA'S CRITICAL ESSAYS}

\begin{abstract}
D. Leonor de Almeida Portugal Lorena e Lencastre (1750-1839), also known as Marquise of Alorna, as a Portuguese poet, translator and essayist, and although it is easily observable how the female presence was left out in the history of Portuguese literature, this woman was present in several literary manuals. Based on the study that has been developed on her translation activity, the present article intends to return to the past in search of traces of her presence in historical-literary criticism, to analyze the extent to which the records of her production contribute for understanding her work, or whether literary criticism only corroborated the secondary role that history, whether literature or universal, gave to women.
\end{abstract}

Keywords: Marquise of Alorna, women's literary criticism, women's literary history

\author{
Procuramos as escritoras \\ as vozes onde elas estão \\ teimamos nas suas vidas \\ E se a escrita foi seu chão \\ Vamos atrás das palavras \\ através do tempo ido \\ encontrá-las recolbidas \\ No passado desvalido \\ Maria Teresa Horta ${ }^{2}$
}

\footnotetext{
${ }^{1}$ Doutoranda do Programa de Pós-Graduação em Estudos Literários pela UNESP - Faculdade de Ciências e Letras de Araraquara. (CAPES).

${ }^{2}$ Cf. HORTA, 2009, p. 44-5.
} 


\section{Introdução}

A História, com $\mathrm{H}$ maiúsculo, aquela que aprendemos na escola e entendemos como a organização dos fatos através do tempo, carrega em si, justamente, o peso de ser a narração desses fatos. O que é deixado de lado, provavelmente de propósito, é que essa "História", agora com aspas, é contada por pessoas, que assumem um ponto de vista, e que "por mais que lutemos arduamente para evitar os preconceitos associados a cor, credo, classe ou sexo, não podemos evitar olhar o passado de um ponto de vista particular" (BURKE, 1992, p. 15). O contexto da escravidão, por exemplo, ou a presença das mulheres nos eventos históricos foram praticamente apagados dessa "História", como é o caso da participação feminina na Revolução Francesa (PERROT, 2005, p. 464), por exemplo. Diversos grupos foram comumente deixados à sua margem, o que, com o passar dos anos, estabeleceu e reforçou o que era central e o que era periférico para a sociedade (BURKE, 1992, p. 12). Nesse sentido, é somente a partir da Escola dos Analles que

a nova história começou a se interessar por virtualmente toda a atividade humana. 'Tudo tem uma história', como escreveu certa ocasião o cientista J.B.S. Haldane; ou seja, tudo tem um passado que pode em princípio ser reconstituído e relacionado ao restante do passado (BURKE, 1992, p. 11).

Evidencia-se, assim, a necessidade de revisitação da História para uma retomada desses agentes "esquecidos". Essa retomada histórica também tem seu lugar na literatura, uma vez que, como a História, o Cânon também é definido, discutido e apresentado a partir não de uma visão universal, mas sob o ponto de vista de um indivíduo, isto é, a partir de

um princípio de seleção (e exclusão) e, assim, não pode se desvincular da questão do poder: obviamente, os que selecionam (e excluem) estão investidos da autoridade para fazê-lo e o farão de acordo com os seus interesses (isto é: de sua classe, de sua cultura, etc.) (REIS, 1992, p. 70).

A partir do princípio de revisão e retomada históricas, este artigo pretende colocar em foco a maneira como se deu a presença feminina na literatura, partindo especificamente da análise dos textos histórico-crítico-literários que abordem a Marquesa de Alorna e sua produção poética, ou seja, é um ato de revisitação, olhando para trás (TELLES, 1992, p. 46), procurando, assim, trazer para a cena e questionar a maneira como a crítica literária abordou, e aborda, a literatura feita por mulheres, procurando apontar em que medida essa abordagem facilitou ou dificultou o acesso que se teve e se tem de sua literatura. 


\section{A mulher e a literatura}

Em 1929, em uma palestra que depois virou um livro intitulado $A$ room of one's own, Virginia Woolf relata sua dificuldade e sua relação com os espaços públicos, especialmente aqueles dedicados à leitura e aos livros, e sua percepção da ausência quase total de escritoras mulheres, creditando esse fenômeno ao espaço ocupado pelo feminino, isto é, o espaço privado. No entanto, o espaço privado para a mulher da época não quer dizer espaço particular, de modo que a dedicação a um trabalho como a escrita termina seriamente comprometido, daí o título de sua obra, a autora acreditava que era preciso dinheiro e um quarto, isto é, um espaço individual, para que, então, a mulher pudesse produzir literatura.

Por mais que as observações de Virginia Woolf façam sentido para uma análise do modo como a mulher vivenciava os espaços e suas relações, é fácil observar que faz muito que as mulheres escrevem, Christine de Pizán e seu La cité des dames (2010), que data de 1405, é prova da presença feminina na literatura desde a Idade Média. O que se torna evidente com essa constatação, então, é a ausência de registros dessa produção, além da parca distribuição e do pouco, ou nenhum, espaço que foi dado às mulheres, seja na história factual, seja na história literária.

Nesse sentido, a Escola dos Analles preconizou pesquisas no que se convencionou chamar de "nova história", que propõe uma nova mirada para História já estabelecida, com a intenção principal de destacar o que, até então, foi marginalizado. Assim, tendo como ponto de partida que a escrita feminina foi, historicamente, segregada pelo cânone, propõese aqui a análise do modo como se deram, através do tempo, os poucos casos em que a crítica literária se debruçou sobre autoras mulheres, especificamente no caso da Marquesa de Alorna.

Os motivos pelos quais uma sociedade patriarcal opta, desde os primórdios, por constituir sua História, e consequentemente seu cânone, deixando de lado a participação feminina, explicam-se por si sós. Esse pensamento está tão arraigado no imaginário popular que até a atualidade a versão da mulher como "anjo do lar", ainda que modificado pelo trabalho das revoluções feministas, está presente no cotidiano da sociedade.

Quando o olhar volta-se para o passado, esse estereótipo parece ainda mais cristalizado, e a mulher mal consegue colocar-se fora dele. Exemplo desse lugar feminino está presente na obra de Luis Antonio Verney, O verdadeiro método de estudar (1746), que foi 
particularmente importante para a história de Portugal, pois introduziu no país as ideias que efervesciam no restante da Europa, especialmente no que diz respeito à educação, o que levou à expulsão dos Jesuítas pelo Marquês de Pombal. O livro, publicado em dois volumes, estrutura-se em formato de cartas, contendo indicações sobre o estudo das disciplinas que Verney considera fundamentais, de acordo com o ideal iluminista da época. No segundo volume, na décima sexta carta, é quando o autor irá tocar no assunto da educação feminina, procurando dar "uma ideia, do modo de instruir as mulheres; e não só nos estudos, mas na economia, com utilidade da República” (1746, v.2, p. 253)³. Em nenhum momento Verney questiona a capacidade feminina em relação à masculina, mas nota-se que durante todo o seu método ele se dedica a defender que os homens possam estudar filosofia, literatura, medicina, teologia, entre outros, enquanto às mulheres a questão baseia-se na "necessidade" (v.2, p. 292), quer dizer, enquanto seja útil a educação feminina para uma boa economia doméstica. Assim, frente a tudo o que é oferecido ao homem, o estudo que é oferecido à mulher é muito menos abrangente. Deste modo, temse uma ideia do lugar destinado à mulher na sociedade portuguesa na época da Marquesa de Alorna.

\section{A autora: Marquesa de Alorna}

D. Leonor de Almeida Portugal Lorena e Lencastre, poeta, escritora e tradutora portuguesa, nasceu em Lisboa, em 1750 e viveu até 1839. Sua biografia é bastante extensa e com diversas curiosidades, o que foi amplamente explorado pela crítica e pela história literária, em muitos momentos em detrimento de sua obra. Tais percalços em sua biografia têm início quando D. Leonor tinha apenas oito anos, quando, insatisfeitos com as medidas do Marquês de Pombal, que privilegiava a burguesia em detrimento da alta nobreza, os Marqueses de Távora - avós de D. Leonor - e de Aveiro intentam contra a vida do Marquês de Pombal. Por azar daqueles, quem estava na carruagem atacada era o rei D. José I. Assim sendo, o secretário de estado conseguiu argumentos para executar os autores do atentado (BRAGA, 1984, v.4, pp. 151-2), o que fez de maneira brutal em praça pública. Na altura, também os descendentes dos condenados eram castigados e desonrados, o que fez com que o Marquês de Alorna, pai de D. Leonor, fosse encarcerado no Forte da Junqueira, e ela, sua mãe e irmã, encerradas no mosteiro de Chelas, bairro de Lisboa, onde ficaram por

\footnotetext{
3 As citações de textos antigos tiveram suas grafias atualizadas, manteve-se as pontuações e maneiras de escrita.
} 
mais de dezoito anos, tendo permissão para sair apenas em 1777, quando da morte do rei, da decadência de Pombal e da coroação de D. Maria, mais favorável ao status quo da aristocracia do que seu antecessor (ANASTÁCIO, 2007, p. 19).

Como é de se imaginar, o longo período que D. Leonor teve de suportar a prisão não foi fácil, o poder do Marquês de Pombal e sua perseguição continuavam, conforme contam as filhas de D. Leonor, Henriqueta e Francisca, na bibliografia que acompanha suas Obras completas (1844), o que é agravado por frequentes adoecimentos maternos e a saudade do pai. No entanto, é nessa época que sua produção é mais profícua, bem como são dessa época seus poemas mais elogiados. A jovem aproveita para, sob a supervisão paterna por meio de correspondências ${ }^{4}$, ampliar em muito sua educação, estudando línguas como o latim e o inglês, bem como música, e desenvolvendo, através de leituras e conversas com o pai, o seu gosto e conhecimento poético. Além disso, a vida no convento lhe proporcionava a participação nos outeiros poéticos, ocasiões em que era permitido às internas o contato com pessoas de fora, oportunidades em que D. Leonor e a irmã declamavam suas poesias e cantavam, estabelecendo relações, como as com poetas como Filinto Elísio - que deu a D. Leonor o nome árcade de Alcipe -, Correia Garção, entre outros representantes da Ribeira das Naus que as visitavam nas grades do convento, além de sua amiga, a Condessa do Vimieiro. Dessa forma, mesmo estando enclausurada, a poesia de D. Leonor pôde ultrapassar os muros e alcançar leitores e conhecimento.

Além dos acontecimentos referentes ao seu período em Chelas, provavelmente um dos mais explorados pelos críticos e historiadores literários, há outros acontecimentos que marcaram sua biografia, como a viagem à Áustria, pouco depois de seu casamento com o Conde de Oyenhausen, e seu aprofundamento no conhecimento da língua alemã, que lhe permitiu o contato com as fontes pré-românticas deste país, além do inglês, que ela já dominava. Outro episódio importante em sua biografia, mas muito pouco explorado, tendo restado ainda diversos pontos a serem esclarecidos, é seu envolvimento em relação à invasão napoleônica, o que levou ao seu exílio em Londres, onde permaneceu de 1803 até 1814, incluindo aí uma tentativa de retorno à pátria em 1809, mas seu desembarque não foi permitido.

\footnotetext{
${ }^{4}$ Cf. Correspondências (usos da carta no século XVIII). Coord.: ANASTÁCIO, V. Lisboa: Edições Colibri e Fundação das Casas de Fronteira e Alorna, 2005 e Inéditos, Cartas e outros Escritos. Prefácio: CIDADE, H. Lisboa: Livraria Sá da Costa Editora, 1941.
} 
A partir desses conhecimentos prévios das principais passagens da vida de D. Leonor, o presente artigo procurará demonstrar como os dados biográficos da Marquesa de Alorna são frequentemente mais explorados por aqueles críticos e historiadores literários que a trazem como figura "quase" canônica da literatura portuguesa do século XVIII e início do XIX. No entanto, os fatos políticos que permeiam sua ida a Londres, ou até mesmo um panorama mais consistente do que ocorreu em sua ida à Áustria ou a Madrid, pouco antes de seguir para Londres, são muito pouco explorados, talvez porque demonstrem sua importância, seu pioneirismo e seu papel político no período. Apenas nos dias de hoje, com o trabalho da Professora Vanda Anastácio, da Universidade de Lisboa, de retomada de escritoras portuguesas anteriores ao Novecentos ${ }^{5}$, e especialmente em sua pesquisa acerca da produção e da vida da Marquesa de Alorna, que esses tópicos vêm sendo estudados e esclarecidos com mais afinco. Assim, uma das constatações a que chega este artigo é a frequente valoração da biografia em detrimento da produção literária, e, ainda assim, essa biografia não se preocupa em mostrar, ou se preocupa em não mostrar, os aspectos em que a Marquesa de Alorna mais destoa da imagem da mulher como "anjo do lar".

\section{A crítica}

Levando em consideração que a escolha dos fatos históricos que entrarão para a história, por assim dizer, fazem parte da manutenção das relações de um poder já estabelecido socialmente, a constituição da história ou de um cânone passa a ser, então, considerada um ato político. Da mesma forma, reconhece-se também como um ato político a retomada histórica das escritoras marginalizadas pela crítica literária (CALEGARI, 2012, p. 30), e um ato de resistência uma vez que procura remediar a ausência e a marginalização feminina na história da literatura.

A questão é que D. Leonor de Almeida, a Marquesa de Alorna, não foi propriamente uma dessas mulheres esquecidas pela crítica, em uma breve análise da história literária, como a realizada aqui, pode-se observar que há uma quase completa ausência de escritoras antes dela, e, mesmo em seu período, ela é uma das poucas a figurar entre os autores literários. No entanto, vale observar como se dá essa crítica e em qual medida ela colaborou para que a Marquesa de Alorna tivesse o devido reconhecimento da importância de sua obra.

\footnotetext{
${ }^{5}$ Cf. o website http://escritoras-em-portugues.eu/
} 
A análise aqui apresentada tem como ponto de partida a primeira publicação de uma biografia da Marquesa de Alorna, em suas Obras completas (1844). Um ano antes, Antonio Feliciano de Castilho, em artigo n'O panorama, noticia a edição que está a ser efetuada por suas filhas

O que d'ela se possuía dava desejos de se conhecer o mais, que os bons e maus dias de sua variada existência lhe haveriam inspirado. Suas filhas, não menos herdeiras do seu talento e amor às letras, que do seu nome, acudindo a estes desejos do público, vão levantar à memória da ilustre dama um padrão, que igualmente o ficará sendo de sua filial ternura. A colecção completa das obras da Sra. Marquesa d'Alorna, irá precedida da sua vida. [...] (CASTILHO, 1843, p. 292)

A biografia, creditada a Henriqueta e Francisca, filhas de D. Leonor, está no primeiro dos cinco volumes de suas obras, é um texto bastante extenso, contendo também detalhes da vida do pai delas, o Conde de Oyenhausen, e árvores genealógicas da família. Tendo sido escrito pelas filhas da biografada é de se considerar, então, que o texto claramente irá soar elogioso e procurará enfeitar passagens, destacando as que melhor farão a construção da personalidade da mãe. Embora haja no texto a intenção de marcar a importância dessa mulher, já é possível notarmos a ausência do aprofundamento nos aspectos da participação política da Marquesa de Alorna. Pouco provavelmente isso se dê por falta de conhecimento das autoras, mas por uma necessidade de mostrar o recato da mulher biografada, bem como mostra-la como vítima dos acontecimentos, e não autora deles. Mesmo com a preocupação de amenizar os feitos da Marquesa de Alorna, é perceptível que nesse texto já estão presentes pontos que serão posteriormente encontrados em outros críticos e historiadores literários, destaca-se aqui a utilização do que se pode chamar de topos da modéstia ${ }^{6}$, que se dá também com a amenização, diminuindo suas capacidades literárias e exaltando seus dotes femininos, além da utilização de adjetivos masculinos para qualificar positivamente a autora ou seu texto.

De início, a biografia traz um breve resumo sobre a vida da Marquesa de Alorna, dividindo sua vida em três partes:

Temos pois a considerar a Senhora Marquesa D. Leonor em três épocas principais da sua vida:

\footnotetext{
${ }^{6}$ Entende-se por essa modéstia, no caso feminino, a diminuição da mulher enquanto autora, principalmente em relação ao sexo oposto, o que levou muitas delas a não colocarem seus nomes como autoras de suas obras, como provavelmente seja o caso da Marquesa de Alorna, ao publicar sua tradução da Arte poética, em 1812, em Londres, sob a indicação de "traduzido por uma portuguesa". Segundo Klobucka esse topos é utilizado "desde a Idade Média, é justamente ao seu sexo que as eruditas europeias atribuem o seu alegado déficit da autoridade necessária para escrever” (p. 4).
} 
$1^{\text {a }}$ - Menina e donzela, na vida de seu pai o Marquês D. João d'Almeida: $2^{a}$ - Condessa d'Oyenhausen, na vida do Conde seu marido; e viúva, até a morte de seu irmão: e

$3^{a}$ - Marquesa d'Alorna, depois da morte de seu irmão, e de seus dois filhos. (ALORNA, 1844, v.1, p. vi)

Já nesse curto excerto destacam-se duas questões, de certa forma conectadas entre si. A primeira delas é a observação do nome adotado por D. Leonor, que só passa a adotar o título de Marquesa de Alorna, pelo qual se tornou mais conhecida nos manuais de literatura, depois da morte de seu sobrinho, de seus filhos e de seu irmão, em 1813, isto é, apenas com a morte de todos os homens da família é que lhe é permitida a posse do título paterno. Outro ponto, agora não relacionado à convenções sociais, como o é a titulação de nobreza, é a cronologia que suas filhas estabelecem como partida para apresentar a vida desta mulher, quer dizer, sua vida está sempre atrelada à uma figura masculina, primeiro ao pai, depois ao marido, não apenas pela utilização de seu sobrenome, mas também pelo título de viúva, que a acompanha até a morte do irmão, quando passa a utilizar outro título, e mesmo quando ela passa a "existir" independentemente, fica claro que isso se deu pela morte do irmão e dos filhos, isto é, apenas quando não restam varões na família.

Como dito anteriormente, algumas problematizações que serão recorrentes na crítica da Marquesa de Alorna já se anunciam nesta biografia das Obras completas, como os dois exemplos a seguir:

É pois no retiro de Chelas, e no apertado encerro em que ali se achava confinada, que esta menina, sem mestres, e sem outro auxílio mais que um gênio muito elevado, a doutrina e ternura de sua mãe, e as máximas e conselhos de seu pai, que passados alguns anos lhe eram regularmente comunicados, com grande perigo seu, e risco de ambos; e com o auxílio de livros escolhidos, que os amigos de sua família lhe facilitavam, se tornou insigne pelo conhecimento das línguas e das letras, pelo da sã Filosofia, da Música e da Poesia, sem que lhe fossem estranhas as outras prendas de seu sexo. (ALORNA, 1844, v.1, p. xvi, grifo nosso)

Entrou na Espanha pela estrada da Catalunha; passou pelo Col de Balaguer, onde foi assaltada por ladrões, de cujo perigo a salvou sua presença d'espírito, e o seu ânimo varonil. (ALORNA, 1844, v.1, p. xxvi, grifo nosso)

Esses períodos manifestam o que se configura como uma das possibilidades do topos da modéstia, citado anteriormente. Mesmo que não seja a própria Marquesa de Alorna a falar, observamos aqui que há a preocupação por parte das biografistas em amenizar tudo o que a mãe conquistou e realizou, ressaltando que mesmo tendo se dedicado aos estudos e se saído muito bem em seus versos, D. Leonor não deixou de desenvolver todas as 
"prendas de seu sexo" e essa informação precisa vir ladeando a que destaca suas capacidades literárias. Por sua vez, o segundo trecho traz outro aspecto que também será bastante comum entre os críticos literários, a utilização de adjetivos masculinos para qualificar positivamente alguma característica da poeta, no caso é utilizado o termo "varonil", adjetivo provindo de "varão", assim, para qualifica-la de forma positiva, o faz sob um ponto de vista patriarcal.

Se é comum a utilização de termos masculinos para adjetivar as qualidades da poeta, é ainda mais comum o uso do termo "varonil", que referencia diretamente ao masculino. Esse vocábulo está presente em Maria Amália Vaz de Carvalho ${ }^{7}$, que, em um estudo (1912) sobre a Marquesa de Alorna, afirma "As duas qualidades predominantes desta inteligência de mulher são o vigor quase viril do pensamento experimentado, e a extrema cultura adquirida em longos anos de prisão" (apud ANASTÁCIO, 2005, p.11, grifo nosso).

O termo também está presente em Hernâni Cidade, que apresenta D. Leonor como "Formosa e altiva silhueta em que a graça feminina se casa com aquela varonil energia que, evitando-lhe as deliquescências sentimentais, lhe inspira um nobre amor da cultura, da liberdade - e o ódio másculo contra o despotismo de que foi vítima" (CIDADE, 1933, p. 77 apud ANASTÁCIO, 2005, p. 13, grifo nosso). Este trecho elogia a Marquesa de Alorna indo muito além do uso de adjetivos varonis, expressivamente o crítico brinca com o "casamento" entre a "graça feminina" e a "energia varonil", simbolizando sua singeleza como mulher, mas também a força com a qual combateu o despotismo do Marquês de Pombal. Cidade tece ainda outro elogio para a poeta, desta vez destacando o fato de ela evitar as "deliquescências sentimentais", como se dissesse que não era uma "mocinha frágil", mas possuidora de um ódio másculo contra as injustiças pombalinas; assim, Cidade reforça a associação do frágil com o feminino, enquanto a força é associada ao masculino.

Uma segunda marca que pode ser observada na análise da fortuna crítica da poeta é a presença, incomum quando se trata de autores do sexo masculino, de elogios à aparência da escritora. Exemplo disso está presente neste mesmo trecho de Hernâni Cidade, quando faz menção a D. Leonor de Almeida como uma silhueta "formosa e altiva". Parece que às mulheres é exigida a beleza, enquanto aos homens é quase sempre indiferente, temos, por exemplo, informações de que Antônio Feliciano de Castilho ficou cego quando criança, mas nada que nos diga se ele era formoso e altivo, inclusive, muitos manuais acabam por

${ }^{7}$ Foi a primeira mulher a fazer parte da Academia das Ciências de Lisboa. (ANASTÁCIO, 2005, p. 11) 
dispensar essa informação. Outra amostra deste caso está em Glórias portuguesas (1869), de A. A. Teixeira de Queirós, em um capítulo dedicado à Marquesa de Alorna:

Foi das mais ilustres entre as damas portuguesas do século passado e do presente. Ninguém conhecia melhor que ela as línguas mortas e vivas e a literatura antiga e moderna; ninguém fazia menor alarde de saber nem manifestava tão desafectada modéstia. Era ornamento da corte, honra da sua família e da pátria. (apud ANASTÁCIO, 2005, p. 11, grifo nosso)

O crítico aqui, além de se valer do topos da modéstia - até elogia seus dons literários, mas parece a ele que a maior qualidade da Marquesa de Alorna foi, justamente, ter sido modesta, sem fazer alarde de seus conhecimentos, - se vale também do vocábulo "ornamento", para apresenta-la como uma bela mulher. O caso é que essa definição parece apagar todas as outras características da autora, deixando-a simplesmente como um objeto, que enfeitava a corte e honrava sua família e sua pátria, mascarando suas atividades literárias e políticas.

Apresentou-se acima uma vertente do topos da modéstia como a necessidade de mostrar que a mulher que escreve não deixa de lado a necessidade de aprender e exercer seu papel feminino na sociedade. Encara-se essa vertente como uma busca por compensação, como se o crítico dissesse: sim, ela escreveu, sim, ela participou da cena política de sua época, mas ela era uma mulher, e não se pode esquecer disso. A exposição dos argumentos dessa maneira está presente em diversos críticos, como em Machado de Assis:

A ocasião é excelente para uns apanhados de estilo, uma exposição grave e longa do papel da mulher no futuro, para uma dissertação acerca do valor da mulher, como filha, esposa, mãe, irmã, enfermeira e mestra, tudo lardeado dos nomes de Rute e Cornélia, Récamier e a Marquesa de Alorna. (ASSIS, 1994, v.III, p. 1004, grifo nosso)

Entre parêntesis, uma patrícia nossa que não perdeu nenhum dos seus belos olhos de vinte e um anos, mostrou agora mesmo que se podem compor versos, sem quebra da beleza pessoal. Não é a primeira, decerto. A Marquesa de Alorna já tinha provado a mesma cousa. (ASSIS, 1994, v.III, p. 663, grifo nosso)

Em ambos os trechos, Machado de Assis coloca a Marquesa de Alorna como exemplo de mulher que conseguiu unir os dotes femininos, com a capacidade de escrita. $\mathrm{O}$ ponto ao qual se quer chegar aqui é que a mulher, para ser considerada escritora, tem que trazer em si diversos outros dotes, que também estarão presentes em suas biografias em manuais de literatura. Não basta que a mulher escreva, ela tem que ser mãe, filha, bela, 
recatada e do lar. Essa mesma busca por compensação entre cultura literária e papel feminino está presente em Esbogos de apreciações literárias, de Camilo Castelo Branco:

Não pode absolutamente dizer-se que a mulher de esmerada instrucção viva toda na ciência e para a ciência. Vão ver um exemplo legado por uma senhora de grande saber. A condessa de Oeynhausen, ilustre portuguesa, foi a um tempo filha extremosa, esposa desvelada, mãe estremecida, e escritora de primeira plana entre os escritores coevos, e a mais abalizada entre as senhoras que a literatura portuguesa considera suas valiosas contribuintes (BRANCO, 1908, p. 121, grifo nosso).

Aqui consegue-se vislumbrar também as questões apresentadas sobre o topos da modéstia anteriormente. É exigido que mulheres da ciência não vivam apenas para a ciência, é preciso que a mulher cumpra com o que a sociedade exija dela, e sua participação na ciência não será o suficiente. Embora no trecho acima Camilo Castelo Branco utilize a Marquesa de Alorna para mostrar que as mulheres conseguem viver na ciência e conjugar sua vida na sociedade, dedicando-lhe em seguida quase dez páginas de biografia, não considera necessário incluí-la no segundo volume do seu Curso de literatura portuguesa (1876), quando fala sobre mulheres poetas. A única aparição do nome de Marquesa de Alorna nessa obra é para mencioná-la como aquela que cunhou o nome árcade de Filinto Elísio para Francisco Manoel do Nascimento (p. 207).

Entretanto, considerando as diversas tentativas de amenizar sua importância e a importância de suas obras, entre diversas críticas misóginas e abordagens predominantemente biografistas, a Marquesa de Alorna também recebeu destaques, tanto de colegas contemporâneos quanto posteriores, e está presente em alguns manuais mais modernos de maneira mais expressiva. Já foi dito aqui que essa autora é uma exceção, pois, por mais que a literatura feminina tenha sido marginalizada, ela esteve presente em manuais de literatura durante todo o período que decorreu de sua morte, tendo sido revista e resgatada contemporaneamente em publicações mais recentes. Vale notar, no entanto, que a crítica que será agora apresentada, embora traga mais pontos positivos do que as até aqui analisadas, também traz em si marcas do topos da modéstia e a preponderância do caráter biografista em detrimento da literatura da poeta.

O próprio Camilo Castelo Branco, em Esboços de apreciaçoes literárias, em um período pouco anterior ao trecho acima citado, questiona o espaço que a literatura dá às mulheres

Em Portugal olham-se de revés as senhoras que escrevem. Cuida muita gente, aliás boa para amanhar a vida, que uma mulher instruída e escritora é um aleijão moral. Outras pessoas, em tom de sisuda gravidade, dizem que a senhora letrada desluz o afectuoso mimo do 
sexo, a cândida singeleza de maneiras, a adorável ignorância das coisas especulativas, e até uma certa timidez pudibunda que mais lhe realça os feitiços. Quer dizer que a mais amável das senhoras será a mais néscia, e que a estupidez é um dom complementar da amabilidade do sexo oposto (BRANCO, 1908, p. 119).

Esse excerto diz muito do que a sociedade pensava de uma mulher das letras, incluindo aí o pensamento de que essa mulher perdia o "mimo do sexo". No mínimo essa informação auxilia a entender o motivo da frequência com a qual os críticos literários insistem no fato de que mesmo sendo escritora a Marquesa de Alorna não perdeu suas qualidades femininas e que cumpriu com zelo seu papel de mãe, esposa e filha. Logo em seguida a esse trecho, Camilo irá explicar, com aquele excerto que se citou acima, utilizando a Marquesa de Alorna como exemplo de mulher que cumpriu muito bem ambos os papeis, assim como procuraram fazer os demais críticos.

Mas também há notícias de autores, como Alexandre Herculano, que se valeram de críticas mais diretas à sociedade para explicar ao que se deveu a Marquesa de Alorna não ser mais reconhecida em sua época

Aquela mulher extraordinária, a quem só faltou outra pátria, que não esta pobre e esquecida terra de Portugal, para ser uma das mais brilhantes provas contra as vãs pertenções de superioridade excessiva do nosso sexo, é que eu devi incitamentos e protecção literária, quando ainda no verdor dos anos dava os primeiros passos na estrada das letras. Aprazme confessá-lo aqui, como outros muitos se a ocasião se oferecesse; porque o menor vislumbre de engenho, a menor tentativa d'arte ou de ciência achavam n'ela tal favor, que ainda os mais apoucados e tímidos se alentavam; e d'isso eu próprio sou bem claro argumento (HERCULANO, 1844, p. 404).

O autor deixa muito claro que são "vãs" as pretensões de que o sexo masculino seja superior ao feminino, destacando o papel que a poeta teve em sua estrada das letras, bem como no caminho de outros autores, e justificando que é por conta da pátria portuguesa que a autora não foi uma das mais brilhantes autoras de seu tempo. Sabe-se que, por mais conservador que Portugal fosse na época, e até mesmo nos anos vindouros, não é uma exclusividade lusitana marginalizar as autoras femininas, muito pelo contrário, a exclusão feminina do cânone literário se deu e se dá em toda a parte, em todos os países ocidentais.

Conforme os anos passam a crítica parece ficar mais preocupada em, além de amenizar a força da poesia da Marquesa de Alorna, complementando que ela cumpriu socialmente seu papel feminino, e de explorar sua biografia, deixar clara a importância dessa autora, seja na sua poesia, na sua tradução ou nos salões que promoveu e na 
influência que exerceu sobre os jovens poetas em inícios do Romantismo, ou seja, houve com o passar do tempo um acréscimo de informações e destaques a características de sua poesia, mas permaneceram pontos críticos.

Um claro exemplo dessa tentativa de colocar a literatura da Marquesa de Alorna em igualdade com a de autores masculinos está no manual de Mendes dos Remédios, História da literatura portuguesa - desde as origens até a atualidade (1914). A obra é organizada por época e gênero literário, e na poesia árcade é possível encontrar o tópico "Duas portuguesas", no qual o autor fala de Marquesa de Alorna e da Viscondessa de Balsemão, ambas apresentadas como "senhoras não menos insignes que muitos dos seus contemporâneos" (p. 468). No entanto, este manual reafirma a utilização de adjetivos masculinos para qualificar positivamente a poesia de D. Leonor de Almeida, uma vez que para Mendes dos Remédios as obras dela "revelam um finíssimo espírito, de uma esmerada cultura, como a podiam ter as mais viris inteligências do Renascimento" (1914, p. 469, grifo nosso). Um ponto em que o crítico destoa dos manuais anteriores aos seus é o destaque que dedica à importância das assembleias e salões literários realizados na casa da Marquesa de Alorna, no entanto, infelizmente, ao chamar atenção para a influência que ela exerceu sobre outros poetas, Mendes dos Remédios acaba por diminuir a importância de sua obra:

Mais, porém, do que pelos seis volumes das suas poesias, o talento da Marquesa de Alorna tornou-se distinto e influi largamente no nosso meio pelos seus salões que reuniam todas quantas pessoas em Lisboa primavam pelo seu saber e pelo seu amor às letras e às ciências (1914, p. 469).

O crítico, para ressaltar a importância das reuniões nos salões da Marquesa de Alorna, acaba por deixar de lado sua produção poética, como se essa também não fosse resultado do seu "saber e amor às letras e às ciências".

Foi dito anteriormente que uma das consequências de D. Leonor de Almeida ter tido uma vida tão atribulada é a exploração que alguns críticos e historiadores literários fazem de sua biografia em detrimento de sua produção literária. Este é o caso de Teófilo Braga, que publicou, em 1918, História da literatura portuguesa, contando com um quarto volume inteiramente dedicado aos árcades. Desde o início de seu capítulo dedicado à Marquesa de Alorna, o autor já esclarece sua visão biografista da poeta, quando lamenta ter sido uma "pena que os documentos da sua atividade literária se limitassem a estas correntes do gosto dominante, não tendo aproveitado o seu talento elaborando as suas memórias pessoais, pela sua larga sociabilidade e participação dos acontecimentos históricos” (1984, 
v.4, p. 242). A partir disso o autor fará sua apresentação da autora tendo como base os acontecimentos de sua vida, incluindo pormenores, tais como "O brusco Arcebispo da Tessalônica, queria que elas ${ }^{8}$ cortassem o cabelo, ao que reagiu Leonor, declarando que não eram noviças; e o impertinente prelado exigindo que não usassem vestidos de cores, dizialhes que elas não careciam de enfeites porque eram muito bonitas" (BRAGA, 1984, v.4, p. 243), ou até mesmo chegando a aventurar-se em desvendar aspectos sentimentais e da consciência da poeta, quando afirma que "D. Leonor de Almeida estava no esplendor da idade e queria deslumbrar os seus admiradores" (BRAGA, 1984, v.4, p. 248).

Especificamente sobre a obra da Marquesa de Alorna, há bem menos informações no livro de Teófilo Braga. Pouco antes do capítulo dedicado exclusivamente a ela, há um nomeado "Proto-romantismo", no qual o crítico trata brevemente da maneira como as influências anglófonas e germânicas chegaram à literatura portuguesa. Neste momento Braga tratará a Marquesa de Alorna como um dos principais nomes desse movimento, mas quando passa a falar da produção poética dela, tecendo breves comentários, não menciona com maiores detalhes sua relação com a poesia que ele chama de proto-romântica. E é só ao final do capítulo a ela dedicado que diz "A sua vida literária confina-se nesses dezoito anos da clausura política nas Albertas de Chelas. Conviveu e foi admirada pelos poetas arcádicos e viu brilhar os iniciadores do Romantismo, mas só retoricamente é que se pode denominar a Staël portuguesa” (1984, v.4, p. 255). Assim, o autor deixa algumas questões no ar: por que apenas retoricamente, se há pouco ele havia falado de seu papel fundamental para a chegada do Romantismo a Portugal? Quais seriam as características de sua obra em Chelas que diferem tanto de sua produção posterior? Sem relacionar mais intrinsecamente a obra e a biografia da autora, a impressão que dá é que o julgamento do valor da produção da poeta não corresponde à importância que ele dedica à sua vida.

Muitos autores concordam e destacam a poesia produzida em Chelas como a principal e mais significativa da extensa produção da Marquesa de Alorna, justamente por ser uma poesia que alia o sentimentalismo, visto como algo inovador, e a natureza, cara à poesia árcade; no entanto, afirmar que "a sua vida literária confina-se nesses dezoito anos da clausura", como o fez Teófilo Braga, além de deixar de lado muito da produção da autora, tal como a tradução e sua importância nesse âmbito, reduz seu papel como poeta. A defesa no presente artigo não é que se elimine a presença de biografias dos autores

\footnotetext{
${ }^{8}$ Ela e sua irmã, D. Maria.
} 
apresentados nos compilados de história da literatura portuguesa, e sabe-se que a da Marquesa traz em si aspectos imbricados à história de Portugal que despertam muito interesse. A questão sobre a publicação de Teófilo Braga é justamente a ausência dos aspectos literários da autora. Um manual de literatura, que pretende traçar a história da literatura do país, sem aprofundar em alguns aspectos literários ou até mesmo citar versos da poeta - vale aqui frisar que no tópico dedicado à Marquesa de Alorna o único soneto que figura é um escrito por Correia Garção, no qual ele versa sobre a beleza dela - é diminuir sua produção, e praticamente mantê-la à margem.

Por sua vez, Hernâni Cidade trata de modo diverso a produção poética da Marquesa de Alorna. Ainda que esse autor tenha tido seu lugar acima com críticas a aspectos de sua abordagem, não se pode deixar de ressaltar sua importância nos estudos e investigações dos autores do Arcadismo e, mais especificamente, dos aspectos que dizem respeito à divulgação da vida e da obra da Marquesa de Alorna, assunto ao qual dedicou diversas de suas obras ${ }^{9}$. Em Lições de cultura e literatura portuguesas, cuja primeira edição data de 1929, o segundo volume é dedicado ao Arcadismo, considerando seus aspectos culturais, históricos e seus autores, entre eles a Marquesa de Alorna. O crítico apresenta, então, uma breve introdução com sua biografia, ilustrando passagens, acontecimentos e relações com poemas dela, como os versos trocados entre ela e Filinto Elísio, que demonstram sua amizade e a troca dos nomes árcades, ou outros, que demonstram episódios de sua vida na clausura (1959, p. 405-414). Assim, Cidade vai na contramão dos críticos e historiadores literários que exploram à exaustão a biografia da Marquesa de Alorna em detrimento de sua obra, uma vez que ele irá se valer dos seus aspectos biográficos para aliá-los à sua poesia. Além disso, Hernâni Cidade realiza um traçado da obra poética da Marquesa de Alorna, considerando uma fase árcade e outra pré-romântica, mas procurando mostrar ao leitor que em sua poesia de Chelas a sensibilidade já figurava em seus versos.

É preciso dizer que, para a crítica, o período Neoclássico não demonstra muitas novidades, diversos autores consideram que a falta de inovação estética desse período não fez com que houvesse muitos aspectos novos e as apresentações são breves, especialmente se comparadas ao Romantismo, em que o advento da noção do "eu", de propriedade do conteúdo poético, bem como da individualidade que essa noção acarreta - vale frisar que

\footnotetext{
${ }^{9}$ Data de 1930 sua primeira publicação sobre o assunto. Cf.: A Marquesa de Alorna - sua vida e obra, com algumas cartas inéditas, Porto: Companhia Porto Editora, 1930.
} 
essa noção perdura até hoje - e que fazem com que o olhar para o Arcadismo seja carregado de julgamentos sobre a cópia e a falta de originalidade. Essa maneira de ler o período está presente, por exemplo, em História da literatura portuguesa ${ }^{10}$ de Joaquim Ferreira, que dedica aos autores desse período não mais do que uma, duas páginas, seguido de uma antologia poética com cerca de dois poemas de cada um deles, isso não seria um problema se essa fosse a proposta do autor para sua obra, mas ao tratar dos autores do Romantismo a abordagem é mais extensa e aprofundada. Embora sejam breves a biografia e a fortuna poética que o autor apresenta da Marquesa de Alorna e que traga apenas dois sonetos da época de Chelas, esse crítico diferencia-se por ressaltar seu trabalho como tradutora:

Foi poetisa de notável estro. Assinava literariamente com o criptónimo "Alcipe". Conhecedora dos principais idiomas europeus, traduziu com abundância: Primavera de Thompson; Oberon de Wieland; Darthula de Ossian; Ensaio crítico de Pope. Todas estas traduções são em decassílabos brancos. E também verteu alguns fragmentos da Ilíada de Homero; a Arte poética de Horácio; os Salmos de David em paráfrases; e outras obras menores. As suas produções originais foram muitas e de grande mérito: dezenas de sonetos, de odes, de cantigas, de epístolas, além de canções, éclogas, elegias, etc., mostram-nos a abundante inspiração de Alcipe. A sua musa não desmereceu na literatura deste período. Os versos afluemlhe com eloquência, as emoções emsombram-lhe o lirismo duma graça merencórea. Nas Obras poéticas, saídas em 1844, há algumas composições excelentes, que fazem da Marquesa de Alorna um espírito escol (FERREIRA, s/d, p. 699).

Antônio Soares Amora também irá dedicar-se a ressaltar as traduções realizadas pela Marquesa de Alorna:

De sua obra poética bastante grande e quase toda publicada postumamente (1844), de significação histórica têm as traduções, pois que introduziram em Portugal os românticos ingleses, alemães e franceses, o melhor é, entretanto, a poesia lírica escrita em Chelas: melancolias da adolescência, sofrimentos morais da prisão (temas que dariam o melhor da poesia da época, com Cláudio, Gonzaga e Bocage) impregnam essas líricas de sincera emoção (AMORA, 1978, p. 250).

Além de defender a poesia de Chelas como o melhor da produção da poeta, Amora também coloca a importância dessa poesia na introdução dos temas românticos na cena literária lusitana. Sobre as traduções, o crítico destaca especialmente o quinto volume de suas Obras completas que contém a tradução da Arte poética, de Horácio, e o Ensaio sobre a crítica, de Pope, consideradas por ele como "as mais importantes de suas traduções" (1978, p. 250).

\footnotetext{
${ }^{10}$ A segunda edição, a qual tivemos acesso, não traz a datação, em uma breve pesquisa pode-se constatar que
} a provável data da primeira edição é de 1939. 
A última das obras a ser aqui apresentada é a História da literatura portuguesa, de António José Saraiva e Óscar Lopes, publicada pela primeira vez em 1955 e que desde então teve mais de 15 reedições e é considerado um dos melhores e mais completos manuais de literatura portuguesa. Embora os autores não realizem uma análise mais aprofundada da obra dos autores, deixando de apresentar até mesmo pequenos exemplos de seus versos, em contrapartida, a obra apresenta uma abordagem que considera a importância dos aspectos sociais de políticos dos períodos apresentados. No que diz respeito à Marquesa de Alorna, é esse tratamento que torna mais acessível o entendimento de sua produção literária, tanto a do período árcade como a considerada pré-romântica, já que os críticos a inserem entre os poetas que se dedicaram a versificar o conhecimento científico da natureza, como é o caso de suas Recriações botânicas (1996, p. 637). Ao contrário de Teófilo Braga, que afirma que a aproximação da Marquesa de Alorna com a Mme. de Staël é somente retórica, Saraiva e Lopes justificam essa aproximação, outorgada por Alexandre Herculano, como já apresentado anteriormente, destacando a influência que a poeta portuguesa exerceu entre seus conterrâneos ao proporcionar salões e assembleias em sua casa:

Os seus salões de S. Domingos de Benfica foram frequentados durante toda a época das lutas civis e ainda depois da vitória liberal por literatos de gerações diferentes, desde os últimos árcades até aos primeiros românticos, como Herculano, que declara dever-lhe o gosto pelo romantismo alemão (SARAIVA e LOPES, 1996, p. 642).

Apresentando um panorama mais completo da vida e da produção da Marquesa de Alorna esses autores conseguem associar claramente os aspectos biográficos aos literários, por exemplo, ao falar das viagens que ela realizou ao lado de suas influências poéticas externas, como Delile, Wieland, Buerger, Goethe, Young, entre outros (1996, p. 642). Com a leitura deste manual conclui-se que a Marquesa de Alorna reflete em sua obra o seu tempo e a grande manifestação de tendências literárias e filosóficas que surgiram no período das Luzes em Portugal e na Europa. Ainda que Saraiva e Lopes definam quantitativamente sua obra como árcade, não deixam de dar o devido destaque às suas traduções modernizantes, ao lado das representantes do legado greco-latino, além, é claro das composições sentimentais e melancólicas do período do convento, em Chelas (1996, p. 642).

\section{Considerações finais}


Procurou-se até aqui apresentar uma certa variedade de abordagens críticas, mas sobretudo destacar que a principal característica da presença da Marquesa de Alorna em manuais de literatura está atrelada à sua vida pessoal, preocupada principalmente em destacar seus dotes femininos, enquanto sua vasta produção é frequentemente deixada em segundo plano.

A constatação de que a história é feita por homens e, portanto, a partir de pontos de vista específicos que levam em consideração aspectos políticos e sociais, preocupados, principalmente, com a manutenção e permanência do status quo já definido, isto é, branco, rico e patriarcal, traz consigo a latência da necessidade de que essa história seja revista e recontada, não por uma voz, mas por muitas vozes, a do negro, do pobre, das mulheres, enfim, das minorias. Concluir que há um ponto de vista na história que se nomeia de universal também leva a questionar a definição do cânone literário estabelecido, afinal, será o mesmo homem, branco e abastado que determinará quais nomes terão lugar na história da literatura.

Recontar a história escrita pelo cânone literário é voltar o olhar ao passado em busca daqueles que ficaram pelo caminho. Claro que nesse sentido muita coisa se perdeu, a escrita é um "monumento mais perene que o bronze", como dizia o poeta latino Horácio, mas o seu suporte não o é. Assim, ter a possibilidade de recontar uma história, voltar aos registros e correspondência de quem teve participação nela é um privilégio.

O movimento que este artigo procurou fazer foi o de voltar o olhar ao passado, procurando não trazer à luz algum autor esquecido, mas observar como a crítica analisou uma autora, entre muito poucas, alçadas à essa condição. Assim, foi possível notar que o tratamento dispensado a uma poeta e a um poeta não se equivalem. É constantemente reiterado, em praticamente todos os manuais de literatura que a Marquesa de Alorna escreveu, mas que ela era uma mulher, e essa condição está atrelada à sua condição de escritora, como se a escrita feminina deixasse marcas no papel que não se encontram nos versos escritos por um homem.

Ao analisar as condições dispensadas às pessoas do sexo feminino, como bem havia destacado Virgínia Woolf, é impressionante que uma mulher, em Portugal, em meados do século XVIII, início do século XIX tenha participado tão ativamente da cena literária, mas não é a isso que os críticos literários se apegam. Como se pode observar pelas análises aqui apresentadas, o apego desses autores é à reafirmação de que, embora ela tenha escrito, 
publicado, influenciado jovens poetas, ela não era nada mais do que uma mulher. Poucos são os que questionam a sociedade em que ela viveu, ou até mesmo os que consideram as qualidades que a levaram a alcançar esse espaço, mesmo sendo mulher.

Assim, a maior parte da crítica literária apenas corrobora o papel que a sociedade destina às mulheres, reforçando seu papel feminino no lugar de destacar seu pioneirismo entre as mulheres literatas de seu país, bem como de destacar suas companheiras, tais como sua irmã e a Condessa do Vimieiro, que também compuseram. São poucos os autores que se preocuparam em apresentar uma compreensão mais global de sua obra, que apresentasse, por exemplo, o que a levou ser mais sentimental no período de Chelas, ou que questionasse se enquanto o marido era vivo sua produção foi menor, ou ainda que verificasse em que momento ela se dedicou mais à tradução. Mesmo as questões relativas à sua aproximação com a poesia inglesa e germânica são supérfluas, e fica comprometido o entendimento de como se deu o seu papel na inserção dessa poesia em terras lusitanas.

Há muito ainda o que se falar sobre a Marquesa de Alorna, tanto sobre sua vida quanto sobre sua obra, como fica evidente a partir das questões críticas apresentadas aqui. É louvável o fato de que ela figure entre os autores de sua época, mas é necessário ressaltar que esses registros demonstram que frequentemente há um "porém", em se tratando de uma autora. Revisitar a história literária criticamente levanta novas perguntas e leva a novos caminhos, e as poetas de nossa literatura merecem esse novo e cuidadoso olhar.

\section{Bibliografia}

ALORNA, M. de. Obras Poeticas de D. Leonor d'Almeida Portugal Lorena e Lencastre, Marquesa d'Alorna, Condessa d'Assumar e d'Oeynhausen, conhecida entre os portugueses pello nome de Alcipe. 5 vols. V. 1. Lisboa: Imprensa Nacional, 1844.

AMORA, A. S. Presença da literatura portuguesa: era clássica. São Paulo - Rio de Janeiro: Difusão Editorial S. A., 1978.

ANASTÁCIO, V. Introdução. In: ALORNA, M. de. Sonetos. Org. Vanda Anastácio. Rio de Janeiro: 7Letras, 2007.

Mulheres varonis e interesses domésticos (Reflexões acerca do discurso produzido pela História Literária acerca das mulheres escritoras da viragem do século XVIII para o século XIX), In: Cartographies. Mélanges offerts à Maria Alzira Seixo. Lisboa, 2005, pp.537-556.

ASSIS, M. de. Obra completa. Rio de Janeiro: Nova Aguiar, 3 vls. v.III, 1994. 
BRAGA, T.. História da literatura portuguesa - Os árcades. v.4. Lisboa: Imprensa nacional - Casa da Moeda, 1984.

BRANCO, C. C. Curso de literatura portuguesa. v.2. Lisboa: Livraria Editora de Mattos Moreira e Cia, 1876.

A Marquesa de Alorna. In: Esboços de apreciações literárias. $3^{\mathrm{a}} \mathrm{ed}$. Livraria Moderna, 1908.

BURKE, P. (Org) A escrita da história: novas perspectivas. Trad. Magda Lopes. São Paulo: Editora da Universidade Estadual Paulista, 1992.

CALEGARI, L. C. O Cânone literário e as expressões de minoria: implicações e significações históricas. In: REVELL - Revista de Estudos Literários da UEMS. Ano 3. v.2. No5. Temático. ISSN: 2179-4456. Dez. de 2012. pp.29-44.

CASTILHO, A. F. Poetisa Portuguesa. In: Revista universal lisbonense. Lisboa: Imprensa Nacional, 1843. p.292.

CATALÃO, R. E, no entanto, elas escreveram! Disponível em https://www.publico.pt/temas/jornal/e-no-entanto-elas-escreveram-26957981, 2013. Visualizado em 24/06/2015.

CIDADE, H. Lições de cultura e literatura portuguesas. 2 vls. Vol. 2. Coimbra: Coimbra Editora Limitada, 1959.

FERREIRA, J. [1939] História da literatura portuguesa. $2^{\mathrm{a}}$ ed. Porto: Domingos Barbosa, s/d.

HERCULANO, A. D. Leonor d'Almeida, Marqueza de Alorna. In: O Panorama. v. $3^{\circ}$, série $2^{\mathrm{a}}$, no156, 21/12/1844. Lisboa: Typographia da Sociedade, 1844, p.403-404.

HORTA, M. T. Poemas do Brasil. São Paulo: Editora Brasiliense, 2009.

JOBIM, J. L.(Org) Palavras da crítica: tendências e conceitos no estudo da literatura. Rio de Janeiro: Imago Ed., 1992. (Biblioteca Pierre Menard)

KLOBUCKA, A. M. O cânone literário português $e$ as mulheres. Disponível em https://www.academia.edu/16572677/O c\%C3\%A2none liter $\% \mathrm{C} 3 \% \mathrm{~A} 1$ rio portugu $\% \mathrm{C} 3$ $\%$ AAs e as mulheres. Visualizado em 24/05/2016.

PIZAN, C. de. La Cité des dames[1405]. Paris: Éditions Stock, 2010.

PERROT, M. As mulheres on os silêncios da história. Trad. Viviane Ribeiro. Bauru: EDUSC, 2005.

REIS, R. Cânon. In: JOBIM, J. L.(Org) Palavras da crítica: tendências e conceitos no estudo da literatura. Rio de Janeiro: Imago Ed., 1992. (Biblioteca Pierre Menard).

REMÉDIOS, M. dos. História da literatura portuguesa - desde às origens até a atualidade. $4^{\mathrm{a}}$ ed. refundida. Coimbra: F. França Amado Editor, 1914. 
SARAIVA, A. J., LOPES, O. História da literatura portuguesa. $17^{\mathrm{a}}$ ed. Porto: Porto Editora, 1996.

TELLES, N. Autor+a. In: JOBIM, J. L.(Org) Palavras da crítica: tendências e conceitos no estudo da literatura. Rio de Janeiro: Imago Ed., 1992. (Biblioteca Pierre Menard)

VERNEY, L. A. Verdadeiro método de estudar. Valência: Oficina de Antonio Balle, 1746.

WOOLF, V. A room of one's own. Reino Unido: Hogarth Press, 1929.

Data de recebimento: 26/04/2017

Data de aprovação: 23/11/2017 